\title{
Fire behaviour of ecological soil-cement blocks with waste incorporation: Experimental and numerical analysis
}

Journal of Fire Sciences 2020, Vol. 38(2) 173-193

(c) The Author(s) 2020

Article reuse guidelines: sagepub.com/journals-permissions DOI: $10.1177 / 0734904$ | I989392 I journals.sagepub.com/home/jfs

\section{Débora Macanjo Ferreira' ${ }^{\prime}$, Eduarda Luso², Maria Lurdes Cruz ${ }^{3}$, Luís MR Mesquita' and Guilherme Gontijo ${ }^{3}$}

Date received: 30 August 2019; accepted: 19 November 2019

\begin{abstract}
The main goal of this study is to assess the behaviour of soil-cement blocks with incorporation of organic wastes. The problem of waste accumulation exists worldwide and has become a concern in today's society, leading to enormous environmental damage. One of the possibilities for reducing their environmental impact is the reuse of these wastes in new materials. However, incorporating waste changes the mechanical, physical and thermal properties of the new material. In order to evaluate the potential use of waste in blocks composition, laboratory tests were conducted and the results were analysed. This article presents the fire behaviour of ecological soil-cement blocks with waste incorporation. Therefore, an experimental programme was performed using samples of wall panel with soil-cement blocks. The wall specimen under fire conditions was also analysed by a non-linear transient finite element numerical model, in time and temperature domains, and the numerical and experimental temperature fields were compared.
\end{abstract}

\section{Keywords}

Soil-cement blocks, sustainable construction, organic wastes, fire resistance

\footnotetext{
'Department of Applied Mechanics, Polytechnic Institute of Bragança, Bragança, Portugal

${ }^{2}$ ISISE, Polytechnic Institute of Bragança, Bragança, Portugal

${ }^{3}$ Polytechnic Institute of Bragança, Bragança, Portugal

Corresponding author:

Débora Macanjo Ferreira, Department of Applied Mechanics, Polytechnic Institute of Bragança, Campus Santa Apolónia, Bragança 530I-857, Portugal.

Email: debora@ipb.pt
} 


\section{Introduction}

In developed countries, the practice of earth construction has fallen into disuse over the past century as a result of technological development and intensive use of new building materials such as concrete and steel. This constructive practice was wrongly associated with an image of poverty, typical of developing countries or extreme situations of housing and economic deprivation. ${ }^{1}$

The increasing interest in earth construction as a sustainable building solution (low $\mathrm{CO}_{2}$ emissions and capacity to return the earthen materials back to nature after their life cycle), led to the development of modern earth construction techniques, and particularly of masonry made of compressed earth blocks (CEBs). ${ }^{1}$ Soil is an abundant raw material, recyclable and reusable, non-combustible, non-toxic, with significant thermal behaviour and without too expensive transformation processes, which allows selecting this material as a major possibility for sustainable construction. ${ }^{2}$ In fact, earth construction can constitute a feasible solution for a more sustainable construction industry in developed countries. However, the major drawback is that traditional earthen materials are typically considered as non-standard. The great variability and heterogeneity of the properties of the available soils as well as the lack of quality control in the manufacture of earthen materials and the construction process can be pointed out as the main reasons behind this situation. ${ }^{3}$ This kind of construction has also disadvantages such as low mechanical strength, which is more concerning in areas considered to be of moderate-to-high seismic risk, as well as low water resistance. ${ }^{4}$ Earth construction also requires regular maintenance to ensure good durability.

The feasibility of earth construction can be analysed by field tests which allow a qualitative knowledge, or by standard laboratory tests that provide quantitative information. Although not all soils can be used for earth construction in their natural state, their particle size correction and/or binder stabilization may allow their use.

CEBs are manufactured resorting to specific press machines, in which the moistened earth is statically compacted in a mould to form the block, which is immediately demoulded and put to dry. ${ }^{1}$ Nowadays, hydraulic press machines can be used instead, allowing for higher compaction pressure, reducing holes and soil porosity, improving material density, and thereby increasing its compressive strength and decreasing its water absorption capacity. ${ }^{4}$ The chemical stabilization of the soils by addition of components (binders) as cement and lime is often used in the manufacturing of CEBs to increase the mechanical properties of the blocks and decrease their susceptibility to variations of moisture. ${ }^{5}$ An advantage of soilcement blocks is the possibility of adding other materials to the mix, especially disposable material, which is an important factor for sustainable construction. ${ }^{6}$ Therefore, soils' characteristics might be analysed when used in the fabrication of blocks, and the influence of different kind of wastes in CEB behaviour shall be studied as well. Previous works have already shown the capability of CEBs with waste addition. For instance, Kraftterra (kraft paper fibres from cement bag recycling) used in the production of CEBs resulted in panel elements with adequate performance and fire resistance. ${ }^{7}$

This research work is part of the VALORCOMP cross-border project, in which the municipal waste management system company ('Resíduos do Nordeste') is one of the partners. The main goal of this study is to assess the behaviour of soil-cement blocks with incorporation of organic wastes, in a wall specimen, when subject to standardized fire conditions. The subject of waste accumulation exists worldwide and has become a concern for today's society, leading to enormous environmental damages. One of the possibilities for reducing 
Table I. Main properties of sand.

\begin{tabular}{lll}
\hline $\begin{array}{l}\text { Particle size distribution } \\
(\text { EN 933-I })^{13}\end{array}$ & $\begin{array}{l}\text { Particle density (Pycnometer } \\
\text { method-EN 1097-6) }\end{array}$ & $\begin{array}{l}\text { Water absorption after 24-h } \\
\text { immersion (EN 1097-6) }\end{array}$ \\
\hline $7.3 \%(0.063-0.250 \mathrm{~mm})$ & $\begin{array}{l}2.601 \mathrm{~g} / \mathrm{cm}^{3} \text { (oven-dried particles) } \\
74 \%(0.250-1.0 \mathrm{~mm})\end{array}$ & $\begin{array}{l}2.605 \mathrm{~g} / \mathrm{cm}^{3} \text { (saturated and } \\
\text { surface dried particles) } \\
2.611 \mathrm{~g} / \mathrm{cm}^{3} \text { (apparent-dried particles) }\end{array}$ \\
\hline $8.7 \%(1.0-4.0 \mathrm{~mm})$ & & \\
\end{tabular}

their environmental impact is the reuse of these wastes in new materials. However, incorporating wastes changes the mechanical, physical and thermal properties of the new material. In order to evaluate the potential use of organic waste in block composition, laboratory tests were conducted and the results were analysed. ${ }^{8}$

An extensive laboratory work was previously conducted, in a first phase in cylindrical specimens (diameter $70 \mathrm{~mm}$ and height $140 \mathrm{~mm}$ ) which allowed to obtain the optimum composition of the CEBs, density, behaviour against humidification drying cycles, water absorption and compressive strength. ${ }^{9}$ This article presents the fire behaviour of ecological soilcement blocks, made with optimal quantities of siliceous sand, kaolin, cement and water, compacted with waste incorporation. At high temperatures, the physical and mechanical changes were evaluated in the tested elements. ${ }^{10}$ Therefore, an experimental programme was performed using a sample of wall panel with soil-cement blocks. Previously, the thermomechanical behaviour on cylindrical samples at different temperature ranges has been studied. ${ }^{11}$ An analysis of residual compression tests is performed from room temperature to a maximum of $800^{\circ} \mathrm{C}$. The wall specimen under fire conditions was also analysed by a nonlinear transient finite element numerical model, in time and temperature domains, and the numerical and experimental temperature fields were compared.

\section{CEBs with waste incorporation}

\section{Materials}

CEBs with incorporation of wastes were manufactured with an artificial soil (mixing $70 \%$ of sand and $30 \%$ of kaolin), cement (10\% of dry soil mass), water and the organic compound ( $20 \%$ of compound in replacement of dry sand volume), provided by the company 'Resíduos do Nordeste'. The use of artificial soil instead of natural soil was due to the fact of attempting to minimize the factors that can influence the final results, since natural soils are very heterogeneous. ${ }^{11}$ The samples used in the residual compression tests had the same compositions as CEB.

The artificial soil was made in the laboratory mixing fine-grained sand from a local supplier $(70 \%)$ and the kaolin Mibal-A from Barqueiros company $(30 \%)$, which allowed to obtain a clay sand (SC) according to the unified classification proposed by ASTM D2487-00. ${ }^{12}$ Table 1 presents some of the properties of the sand used in this study and the standards that support the obtained results.

Table 2 shows some of the characteristics of kaolin presented in the technical datasheet.

In order to ascertain the suitability of the soil to stabilization with cement, particle size analysis and determination of consistency limits are required. The values of liquidity $(W 1=$ $43.5 \%)$ and plasticity $(W p=25.8 \%)$ limits served for the above indicated soil classification. ${ }^{18}$ 
Table 2. Information available in the technical datasheet from the producer of kaolin.

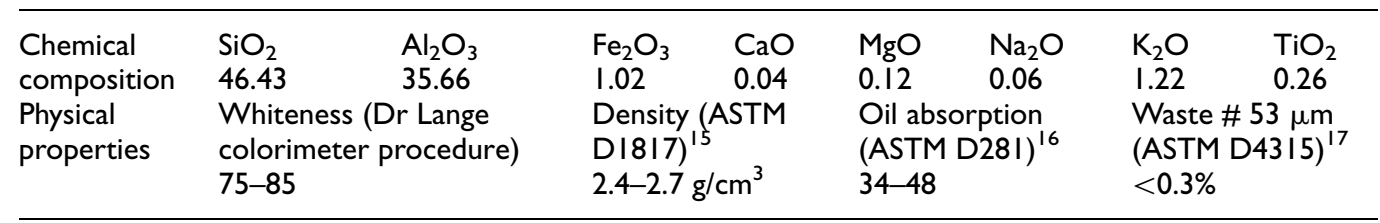

Table 3. Waste composition.

\begin{tabular}{lllllllll}
\hline Humidity & $\begin{array}{l}\text { Organic } \\
\text { matter }\end{array}$ & $\begin{array}{l}\text { Organic } \\
\text { carbon }\end{array}$ & Nitrogen & Phosphorus Potassium Calcium & \multicolumn{2}{l}{ Magnesium Sulphur } \\
\hline $29.6 \%$ & $48.8 \%$ & $27.1 \%$ & $1.3 \%$ & $1.1 \%$ & $1.4 \%$ & $4.9 \%$ & $0.8 \%$ & $0.6 \%$ \\
\hline Boron & Cadmium & Chromium Copper & Mercury & Nickel & Lead & Zinc & Density \\
\hline $43.4 \mathrm{mg} / \mathrm{kg}$ & $0.9 \mathrm{mg} / \mathrm{kg}$ & $130 \mathrm{mg} / \mathrm{kg}$ & $209.7 \mathrm{mg} / \mathrm{kg}$ & $0.4 \mathrm{mg} / \mathrm{kg}$ & $49 \mathrm{mg} / \mathrm{kg}$ & $110 \mathrm{mg} / \mathrm{kg}$ & $453 \mathrm{mg} / \mathrm{kg}$ & $0.45 \mathrm{~kg} / \mathrm{dm}^{3}$ \\
\hline
\end{tabular}

The cement added to the mixture was Portland Lime cement from Secil company, classifies as EN 197-1. ${ }^{19}$ The waste incorporated in the mixture was an organic compound of class IIA quality, ${ }^{20}$ normally used for arboreal and shrubby agricultural crops resulting from the biological treatment of municipal solid waste. Table 3 shows the composition of used waste supplied by the company 'Resíduos do Nordeste'.

Once the soil had been selected, compaction test was performed for the composition to be studied, in order to assess the compaction control values, since soil-cement is the product resulting from the mixture of soil, cement, water and waste that was compacted in the optimum humidity $(w=9.7 \%)$ and under the maximum density $\left(\rho_{d}=2.1 \mathrm{~g} / \mathrm{cm}^{3}\right)$, and acquired resistance and durability through the hydration reactions of the cement. This procedure was conducted according to the ASTM D- $558^{21}$ standard and is described in other works. ${ }^{9}$

\section{Manufacture of residual compression samples}

ASTM D1632 22 was generally followed in the preparation of the test samples. Cylindrical test samples were manufactured by static compaction, with a diameter of $70 \mathrm{~mm}$ and a height of $140 \mathrm{~mm}$ according to the height/diameter ratio of 2 . The specimens were prepared one by one, and the process was started by dry-mixing the previously determined quantities of sand, kaolin, cement and residue. After mixing the dry elements of each composition, the water was combined and mixed by hand until the mixture became homogeneous. This was followed by moulding of the specimens (Figure 1(a)) using the available equipment and compaction was performed with a manual compactor in three layers (Figure 1(b)). These manufacturing conditions were maintained for all test pieces (Figure 1(c)). After shaping the specimens, the wet-chamber curing period was followed in which they were kept at a substantially constant humidity of $95 \%$ and a temperature of approximately $20^{\circ} \mathrm{C}$ until the day of testing (Figure $1(\mathrm{~d})$ ). 


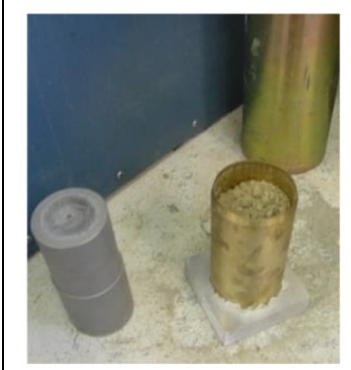

(a)

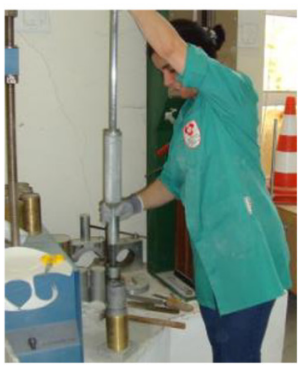

(b)

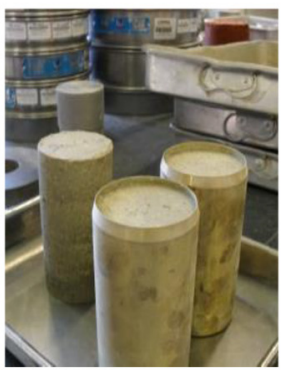

(c)

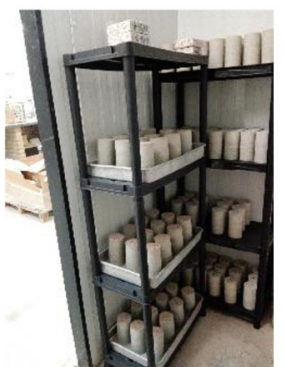

(d)

Figure I. (a) Elements of samples in mould, (b) compaction equipment, (c) compacted samples and (d) samples in humid chamber.

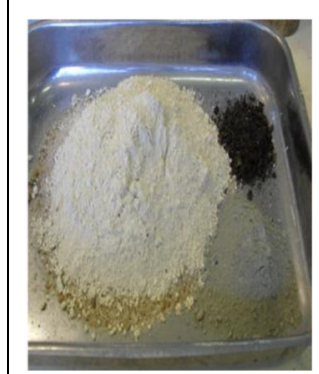

(a)

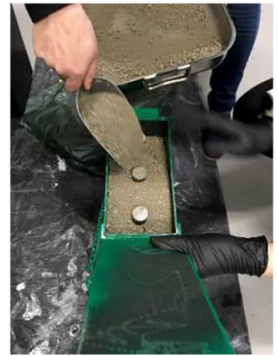

(b)

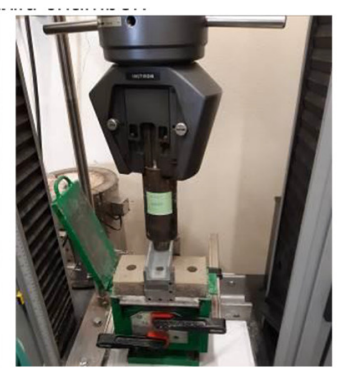

(c)

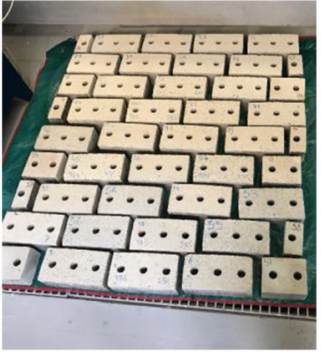

(d)

Figure 2. (a) Dry elements of CEBs, (b) moulding equipment, (c) fabrication of CEBs and (d) CEBs in humid chamber.

\section{Manufacturing of CEBs}

The blocks were moulded individually and the process was started by first drying the sand, kaolin, cement and waste in amounts previously determined (Figure 2(a)). After drying, the elements of composition were mixed, water added and the mechanical mix was continued until the final material showed homogeneity. Figure 2(b) shows the equipment used to mould the CEBs, where the compaction pressure was controlled and maintained in all blocks to avoid differences in density and porosity between them. ${ }^{23}$ The manufacturing conditions were maintained for all the blocks (Figure 2(c)). After moulding the blocks, the curing period was proceeded in a humid chamber in which they were maintained at a substantially constant $95 \%$ humidity and at a temperature of approximately $20^{\circ} \mathrm{C}$, see Figure 2(d).

\section{CEB panel and construction details}

The wall panel with $1 \times 1 \mathrm{~m}^{2}$ area was tested in a fire resistance furnace according to EN 1364- $1^{24}$ applied for non-load-bearing elements. Fire resistance is a measure of the ability of a building element to resist a fire, usually the time for which the element can meet the appropriate criteria during exposure to a standard fire resistance test. Two fire performance criteria were verified, which are the integrity and the insulation. 


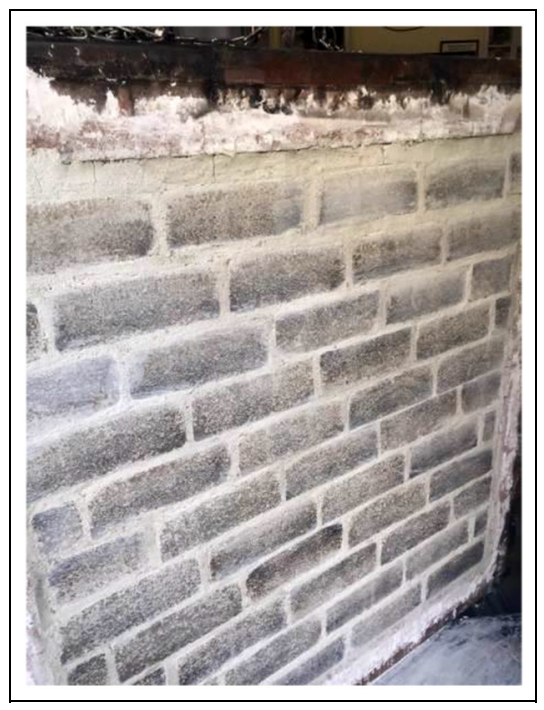

Figure 3. CEB wall panel.

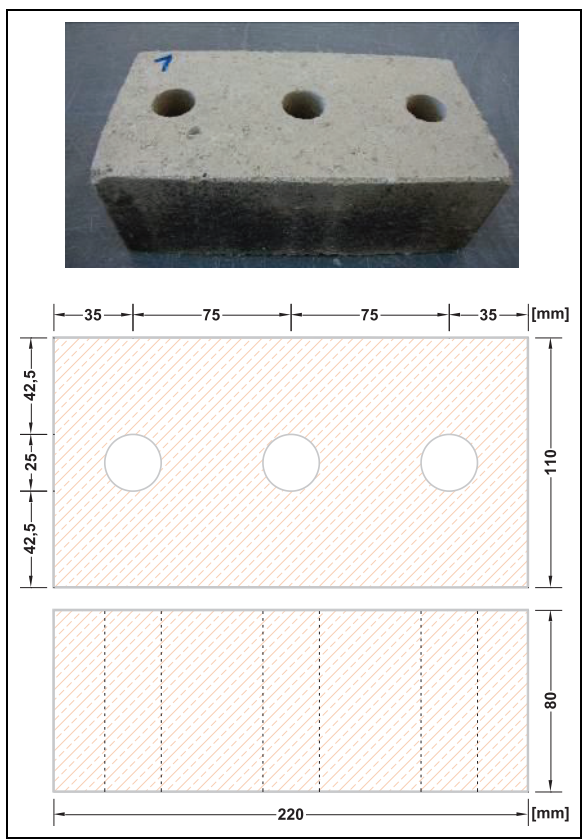

Figure 4. Dimensions of the CEB blocks.

The CEB panels studied were composed of 11 alternating strands organized in three different ways (Figure 3). The geometry of the blocks that form the panel consists of a hollow block with dimensions $220 \times 110 \times 80 \mathrm{~mm}^{3}$ (width $\times$ thickness $\times$ height), as can be seen in Figure 4 . The geometry of the CEBs and the respective building system was based on an 
output from a previous partnership between the University of Minho and the University of Trás-os-Montes e Alto Douro. ${ }^{5}$

The wall panel was made directly on the furnace frame (Figure 5). First, a layer of mortar was placed directly on the frame and then the blocks were positioned. The CEBs were humidified with water before applying the mortar, in order to avoid excessive absorption of moisture from the mortar by the blocks (Figure 6). The applied mortar had the same composition as the CEB without the addition of waste, but with more water, and was applied to the horizontal and vertical settlement faces of the blocks with a fence thickness of $1 \mathrm{~cm}$. The thickness was ensured by applying two planks on each wall face leaving $1 \mathrm{~cm}$ free. The joints between the blocks were also closed (Figure 7), and finally, the wall was cleaned to remove any additional mortar (Figure 8). The CEB wall panel remained in place, after construction for 28 days curing in laboratory conditions.

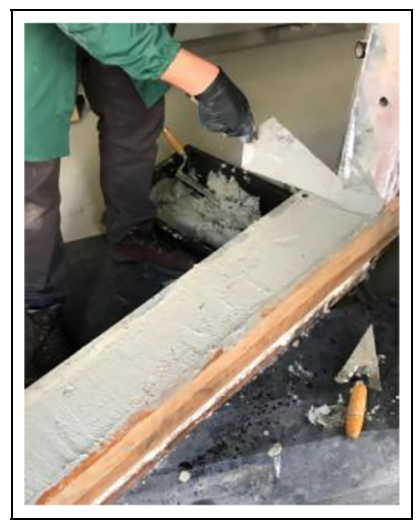

Figure 5. CEB panel made on the furnace frame.

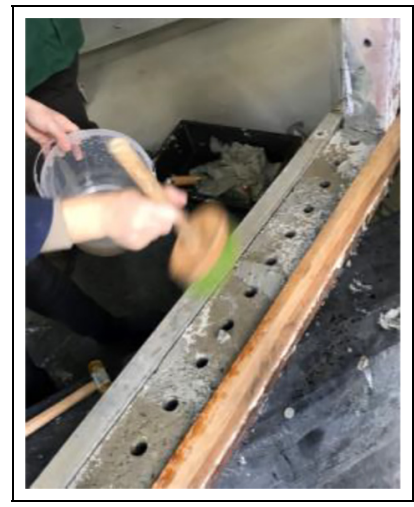

Figure 6. Moistening the CEBs with water. 


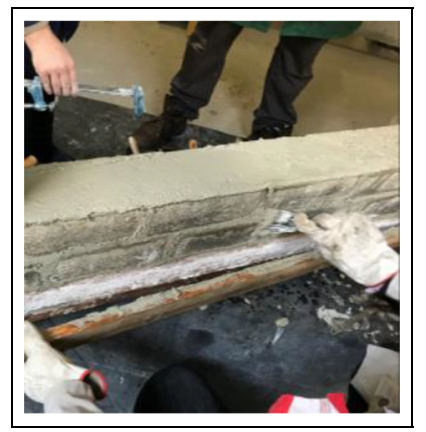

Figure 7. CEB panel joints closure.

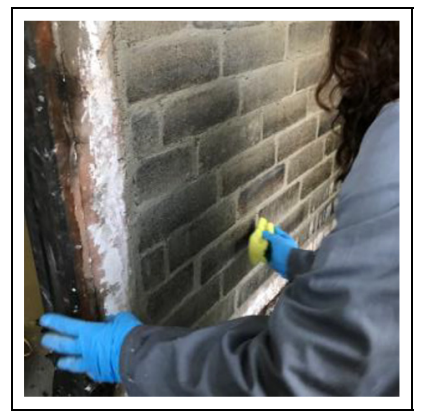

Figure 8. CEB panel cleaning.

\section{Experimental tests}

\section{Residual compression tests}

The fire resistance of structural elements can be evaluated in three main domains, namely the time domain, temperature domain and resistance domain. Regarding the first two, the experimental assessment consists of placing the element in a furnace and varying the temperature over time according to a standard function-standard fire curve. The ISO 834 curve $^{25}$ is the most commonly used for assessing the resilience of building structures, representing a fire in a building. Standard collapse criteria define the collapse time or the critical temperature. In the resistance domain the most usual way to determine the elements' load-bearing capacity in fire consists of submitting the element to a constant temperature in the stationary domain and increasing the mechanical load until collapse.

To evaluate the mechanical resistance, tests were carried out for six different temperature levels: the first test refers to room temperature, $20^{\circ} \mathrm{C}$, followed by $100^{\circ} \mathrm{C}, 200^{\circ} \mathrm{C}, 400^{\circ} \mathrm{C}$, $600^{\circ} \mathrm{C}$ and $800^{\circ} \mathrm{C}$. Once the desired temperature of the specimen was reached, a 15 -min waiting time ensured that the inside of the specimen had reached the desired temperature. After that, the samples were placed on a cooling base for $24 \mathrm{~h}$, and then the cylinders were compressed at the test speed set at $0.6 \mathrm{~mm} / \mathrm{min}$. The temperature of the electric resistance furnace and specimen were controlled until the end of heating. In the test it was possible to 


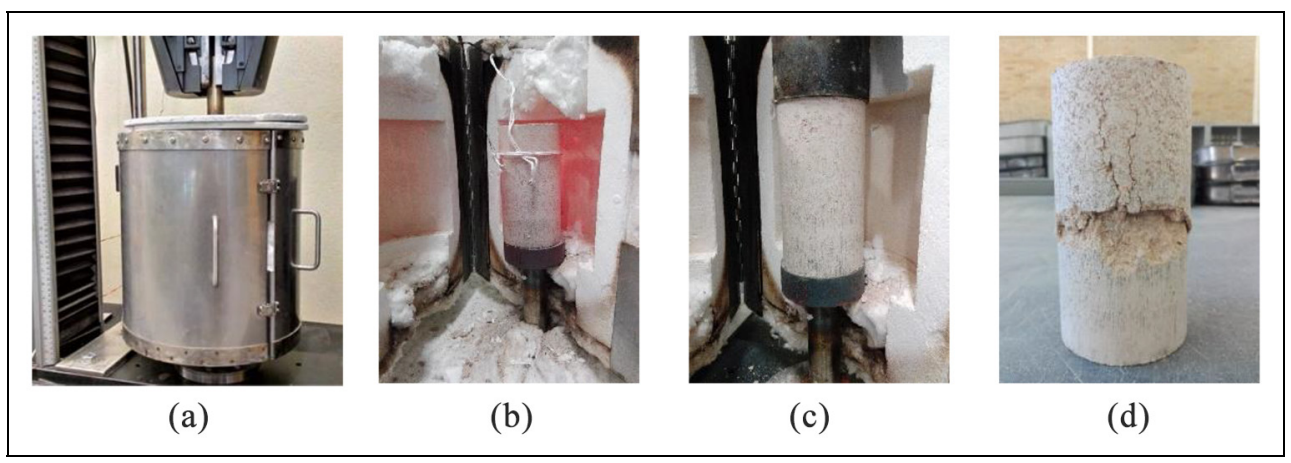

Figure 9. (a) Sample heating, (b) sample after heating, (c) sample before compression test and (d) sample after compression test.

observe the behaviour of the specimen as well as the maximum compression resistance. The test was completed when the specimen reached failure. Figure 9 shows the residual compression test of earth specimens.

\section{Fire test of CEB wall panel}

The thermal behaviour of the CEB panel exposed to the fire was evaluated using several thermocouples for measuring both the internal and external temperatures of the wall. The entire procedure is based on the European standard for the general requirements for fire testing ${ }^{26}$ and the specific requirements for the fire testing of non-load-bearing walls (testing conditions, specimen preparation, specimen fixation, conditioning and instrumentation). ${ }^{24}$ According to these standards, two fire performance criteria should be evaluated through all tests: the insulation and integrity criteria. The fire insulation criterion is the time, in completed minutes, for which the test specimen continues to maintain its separating function during the test without developing temperatures on its unexposed side, which increase the average temperature above the initial average temperature (1) by more than $140^{\circ} \mathrm{C}$ (fire insulation criterion 1) or (2) increase by more than $180^{\circ} \mathrm{C}$ at any location of the unexposed side above the initial average temperature (fire insulation criterion 2). Fire integrity is the ability to prevent fire and smoke transmission through the element. The integrity criterion was verified throughout the experiments by employing a cotton wool pad saturated in ethyl alcohol.

Different types of thermocouples were installed to verify the evolution of the CEB panel temperatures during the test. Simple type $\mathrm{K}$ thermocouples were placed at different depths from the unexposed surface $(27.5 \mathrm{~mm}, 55.0 \mathrm{~mm}$ and $82.5 \mathrm{~mm})$ in order to obtain temperature records inside the block (TB) (Figure 10(a)), in the mortar (TM) (Figure 10(b)), and inside the blocks holes (TH) (Figure 10(c)). The unexposed surface was also instrumented using type-K thermocouples welded on copper discs protected by plasterboard (TD) (Figure 10(d)), used for measuring temperatures at specific panel points in order to assess and verify the insulation criterion. The thermocouples were placed according to Figure 11.

Fire test was performed in a resistance furnace prepared to work with the standard fire curve ISO $834 .^{25}$ At the beginning of the tests, the CEB wall panel was at the ambient laboratory temperature of about $20^{\circ} \mathrm{C}$ and air humidity around was $65 \%$. The ambient air temperature was monitored at a distance of between 1 and $3 \mathrm{~m}$ horizontally away from the 
unexposed face under conditions such that the sensor was not affected by thermal radiation and the ambient air temperature was $20^{\circ} \mathrm{C} \pm 10^{\circ} \mathrm{C}$ (Figure 12). During the test, the integrity of the wall and the insulation of the panel were evaluated by assessing the unexposed surface temperature according to the European standard. ${ }^{26}$

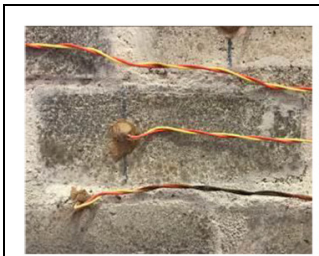

(a)

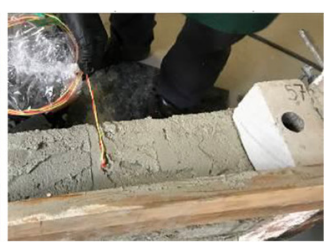

(b)

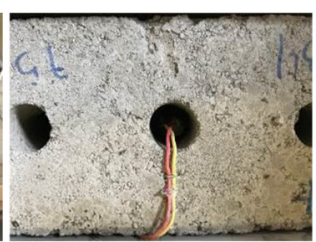

(c)

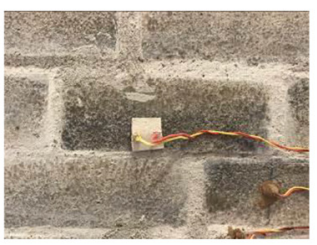

(d)

Figure 10. Type-K thermocouples: (a) inside the block (TB); (b) in the mortar (TM); (c) inside the block holes (TH); (d) unexposed surface (TD).

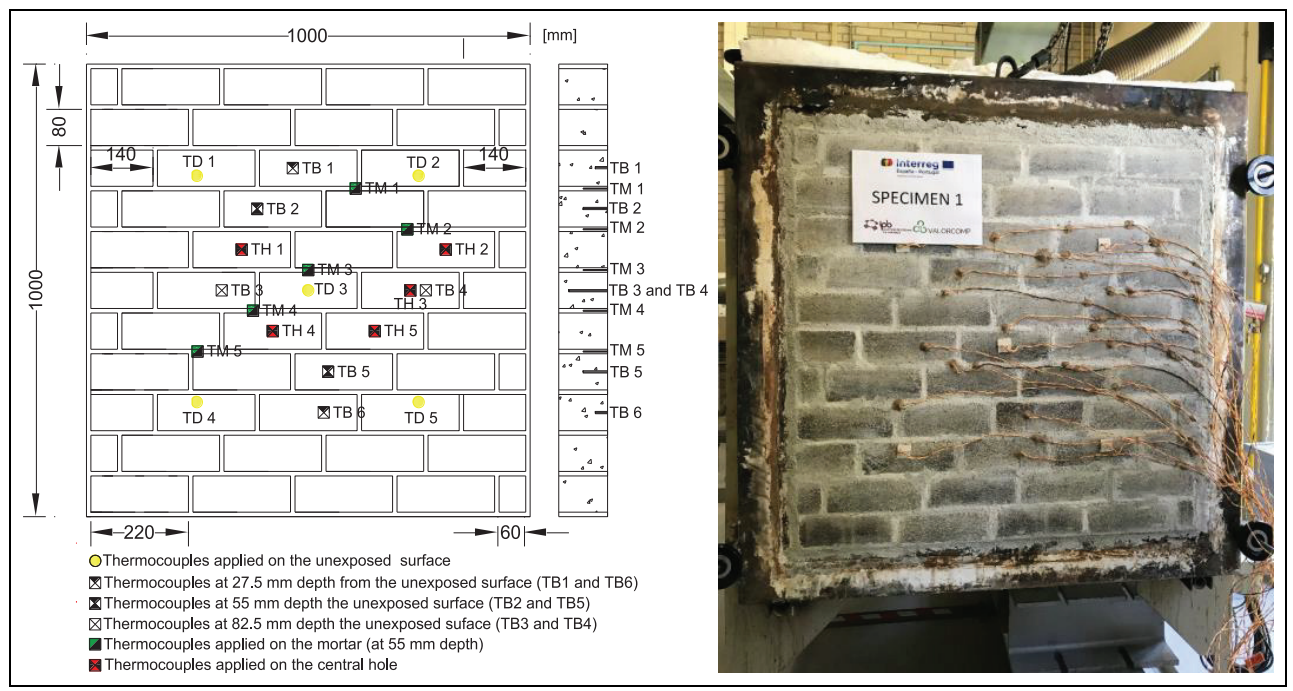

Figure II. Thermocouples location.

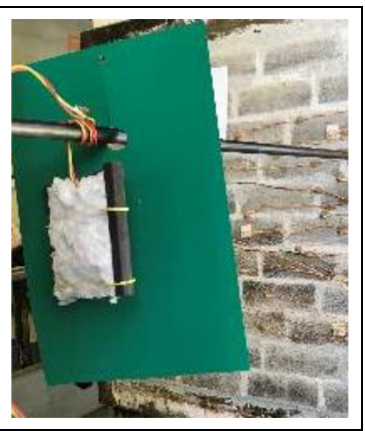

Figure 12. Ambient air temperature monitored. 


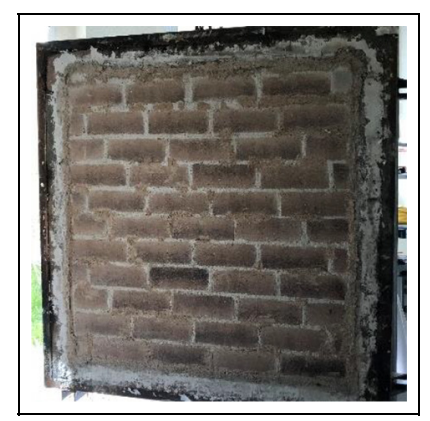

Figure 13. Integrity of the CEB panel.

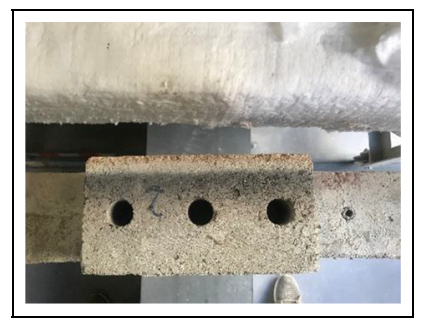

Figure 14. CEBs after exposure to fire.

The test was performed over a time period of 90 min corresponding to a maximum real temperature in the furnace of $1000^{\circ} \mathrm{C}$. It can be observed that the CEBs did not suffer damage nor significant cracks (Figure 13), but small cracks appeared in the mortar which allowed smoke to release from the blocks, leading to burning and compound volatilization. When the wall was disassembled, it observed the change of colour of the blocks due to exposure to fire, as can be seen in Figure 14. Some of these blocks were tested later under compression.

The integrity criterion was also verified because there was no flame or ignitions of the cotton. At the same time, the insulation criterion was verified taking into account that the higher value of temperature measured in thermocouple TD2 was $92^{\circ} \mathrm{C}$.

\section{Numerical analysis}

Although there is a real lack of knowledge about the CEB's thermal and mechanical properties in function of temperature, a preliminary attempt of analysing numerically the complete wall exposed to fire is presented. Detailed information and background about its material thermal and physical properties varying with temperature is given.

The wall was analysed numerically using non-linear transient heat transfer analysis by the finite element method, using the software Ansys ${ }^{\circledR} .{ }^{27}$ The complete wall, CEBs and mortar, was modelled by three-dimensional (3D) Solid90 finite elements. This is a high-order element with 20 nodes and temperatures as a single degree of freedom. The temperature field is determined according to the energy equation (see equation (1)), considering the solid material thermal capacitance and the conduction heat flux. For the solution a heat convergence 
criteria based on the norm of the Newton-Raphson load with a tolerance of $1 \mathrm{e}^{-3}$ and a minimum reference value of $1 \mathrm{e}^{-6}$ was used as

$$
\frac{d}{d t}\left(\rho(T) \cdot c_{p}(T) \cdot T\right)=\frac{d}{d x}\left(k(T) \cdot \frac{d T}{d x}\right)+\frac{d}{d y}\left(k(T) \cdot \frac{d T}{d y}\right)+\frac{d}{d z}\left(k(T) \cdot \frac{d T}{d z}\right)
$$

Convection and radiation were considered in the exposed and unexposed surfaces, taking into account the boundary condition represented as follows

$$
k(T) \frac{d T}{d n}=h_{c} \cdot\left(T_{s}-T_{\infty}\right)+\varepsilon \cdot \sigma_{s b} \cdot\left(T_{s}^{4}-T_{\infty}^{4}\right)
$$

where $k(T), \rho(T)$ and $c_{p}(T)$ are the thermal conductivity, the specific mass and the specific heat for CEBs and mortar. $h_{c}$ is the convection heat transfer coefficient, considered as $25 \mathrm{~W} / \mathrm{m}^{2} \mathrm{~K}$ for the exposed surface and $4 \mathrm{~W} / \mathrm{m}^{2} \mathrm{~K}$ for the unexposed outside surface. ${ }^{28}$ Radiation is also added to both the surfaces, and defined by an emissivity equal to 0.85 to CEBs and mortar, ${ }^{29}$ and the Stefan-Boltzmann constant $\sigma_{s b} . T_{\infty}$ represents the air temperature in contact with the surface, at temperature $T_{s}$, being defined by the standard fire curve ISO834 and the ambient temperature, for the exposed and unexposed faces, respectively.

CEBs are made from compressed earth and are consequently porous. The heat transfer inside the block occurs in different ways, namely conduction in the solid, liquid and gas fractions, convection and radiation in the porous fraction. In addition, endothermic and exothermic reactions happen due to the presence of water and cement. An equivalent thermal conductivity should consider all these heat mechanisms, but for CEBs there is a lack of information of thermal properties varying with temperature.

The model considers the solid specific mass temperature variation from the equation defined in the Eurocode EN 1992-1-2, ${ }^{28}$ for concrete mortar, considering the measured values at ambient temperature. This Eurocode was also used to establish the specific heat and thermal conductivity temperature variation, according to the moisture of mortar. For the CEBs the Eurocode was also used, but to allow for the heat consumed during water evaporation, a specific heat peak was calculated from the measured moisture content and water latent heat of vaporization $(2260 \mathrm{~kJ} / \mathrm{kg})$, assuming that water vaporization occurs between $100^{\circ} \mathrm{C}$ and $200^{\circ} \mathrm{C}$, giving a peak value at $150^{\circ} \mathrm{C}$ equal to $1170+3977.6=5147.6 \mathrm{~J} / \mathrm{kg} \cdot \mathrm{K}$.

Thermal conductivity of CEBs is influenced by several factors, being the most relevant the compaction pressure, block porosity, moisture and cement contents. ${ }^{30,31}$ The work of Zhang et al. ${ }^{31}$ showed that thermal conductivity is much more influenced by the bulk density rather than cement content. This occurs due to the decrease in porosity when the compaction pressure increases, giving a higher bulk density. Scanning electron microscopy (SEM) images from Zhang's work show that for a bulk density of around $2.0 \mathrm{~g} / \mathrm{cm}^{3}$ the CEBs have pores close to $100 \mu \mathrm{m}$ diameter. This pore size can be expected to increase when CEBs are exposed to elevated temperature causing the water content to evaporate. Mansour et al.'s ${ }^{30}$ work to study the influence of compaction pressure and porosity on thermal conductivity gives a porosity equal $26.5 \%$ to CEBs of bulk density equal to $2.06 \mathrm{~g} / \mathrm{cm}^{3}$, and for a moisture content of $3.23 \%$ a thermal conductivity equal to $1.12 \mathrm{~W} / \mathrm{mK}$.

Considering the unknown variation of thermal conductivity with temperature, an effective thermal conductivity was used, considering the average porosity from the Russell model. ${ }^{32}$ This model considered the average porosity $(\varphi)$ as well as solid $\left(k_{s}\right)$ and gas $\left(k_{g}\right)$ thermal conductivities as 


$$
k_{e f f}=k_{s} \frac{\varphi^{2 / 3}+\left(\frac{k_{s}}{k_{g}}\right)\left(1-\varphi^{2 / 3}\right)}{\left(\varphi^{2 / 3}-\varphi\right)+\left(\frac{k_{s}}{k_{g}}\right)\left(1-\varphi^{2 / 3}+\varphi\right)}
$$

The gas thermal conductivity includes the conductive term given by the air conduction heat transfer coefficient, presented in equation (4), ${ }^{33}$ and by an irradiative component as

$$
k_{g}=-1.881 \times 10^{-8} T^{2}+8.38 \times 10^{-5} T+0.002244
$$

Radiation inside porous material was modelled as a series of parallel opaque planes with separation equal to the cell size, giving an irradiative contribution to the total effective conductivity defined in Glicksman ${ }^{34}$ as follows

$$
k_{r}=4 \frac{\epsilon}{2-\varepsilon} \sigma d T^{3}
$$

where $\varepsilon$ is the wall emissivity, taken as $0.85, \sigma$ is the Stefan-Boltzmann constant and $d$ is the pore diameter, considered equal to $160 \mu \mathrm{m}$, based on Zhang et al.'s work ${ }^{31}$ and expected to increase in porous size during fire action. Russell model was applied after water dehydration due to the increased importance of porosity. In order to approximate the experimental and numerical results, an increase in variation between $50^{\circ} \mathrm{C}$ and $100^{\circ} \mathrm{C}$ was used. Figure 15 presents these properties in functions of temperature.

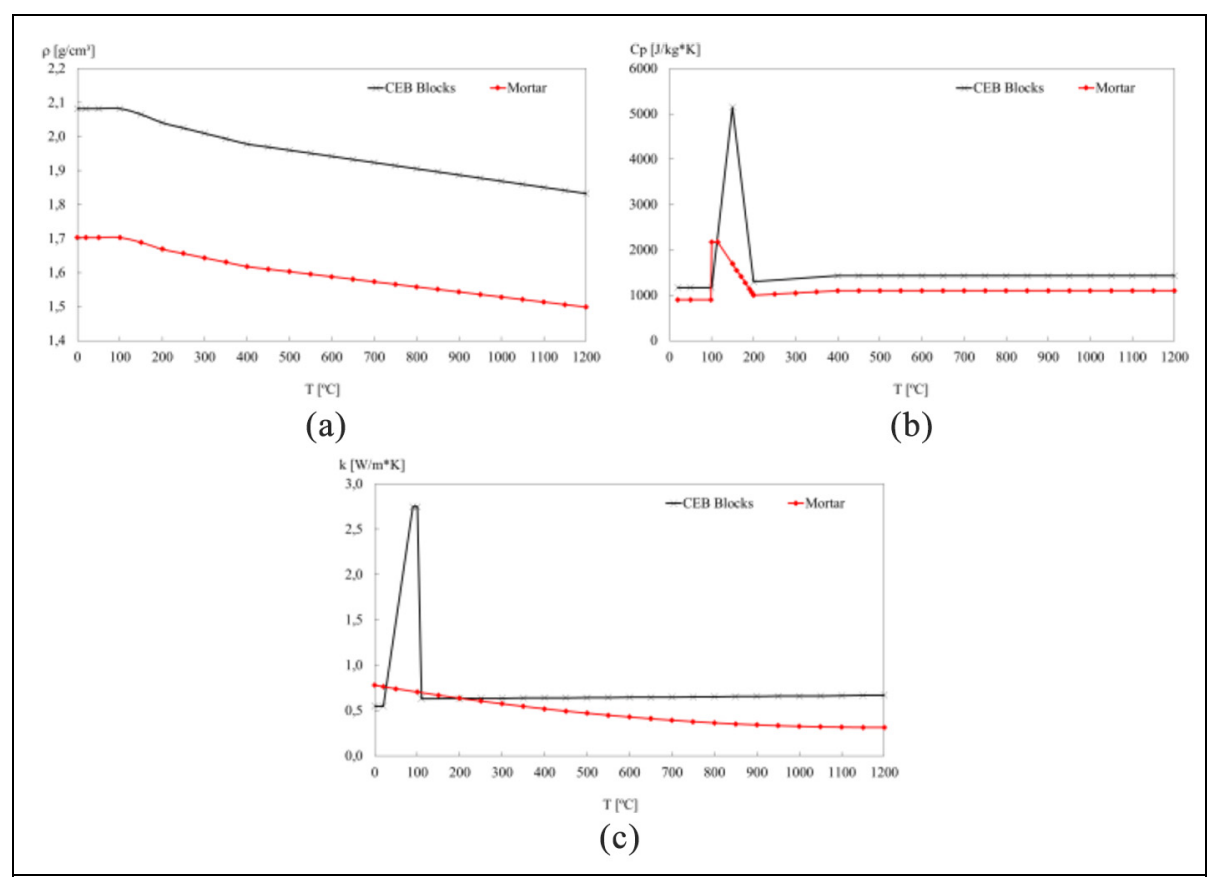

Figure I5. CEB blocks and mortar physical and thermal properties: (a) specific mass, (b) specific heat and (c) thermal conductivity. 


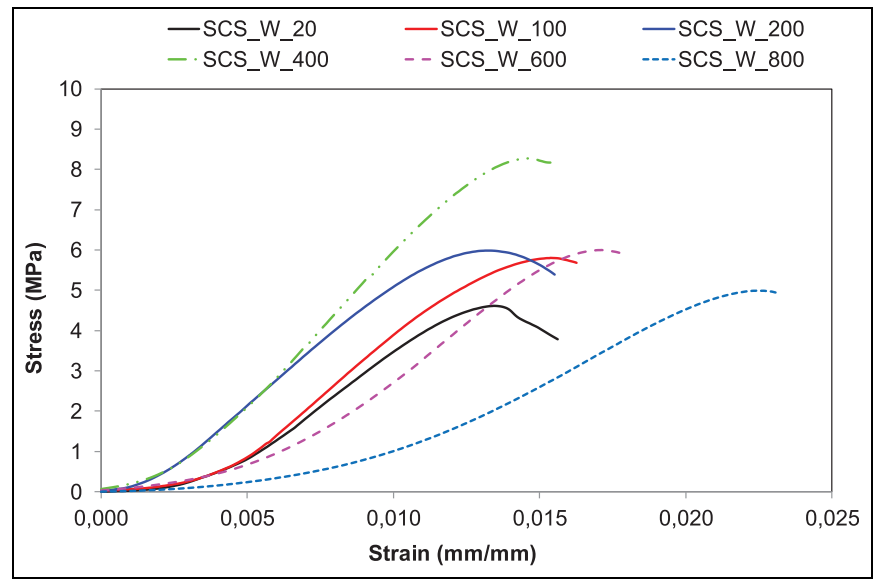

Figure 16. Residual compression test results.

\section{Experimental and numerical results}

\section{Experimental results of residual compression tests}

The results obtained for residual compression tests at six different temperature levels are shown in Figure 16, where SCS_W means compression soil-cement sample with waste incorporation.

The main purpose of the residual compression tests was to determine the mechanical behaviour of samples after a fire situation.

Residual compression tests show that exposure up to $400^{\circ} \mathrm{C}$ results in a compressive strength increase after cooling of the sample. Samples without fire exposure attain 4.6 MPa compressive strength and when subjected to temperatures in the range of $400^{\circ} \mathrm{C}$, this value turn to $8.3 \mathrm{MPa}$, doubling their capacity. Beyond this temperature, the mechanical strength of the specimen's changes and their performance and compressive strength decreases, reaching $4.9 \mathrm{MPa}$ when the specimens are subjected to $800^{\circ} \mathrm{C}$. There is also a change in the colour of the samples when exposed to these temperature levels. Similar conclusions were obtained in previous works of characterization of earth specimens without incorporation of wastes. ${ }^{10}$

\section{Experimental results of CEBs wall panel}

Figures 17 to 20 show the experimental time-temperature evolution of the fire-exposed surface of the CEB wall panels related to the thermocouples located on the CEBs (TB), on the CEBs holes (TH) and on the mortar (TM). Figure 20 shows the temperatures recorded by the thermocouples applied in the unexposed surface of the CEB wall panel.

From Figure 17, it can be seen that thermocouples TB3 and TB4 (which are placed in the block at $82 \mathrm{~mm}$ depth from the unexposed fire surface) recorded the highest temperatures of approximately $400^{\circ} \mathrm{C}$. Concerning the thermocouples located near the unexposed surface ( $27.5 \mathrm{~mm}$ deep), the temperature was $115^{\circ} \mathrm{C}$. The thermocouples placed inside the block hole recorded temperatures between $270^{\circ} \mathrm{C}$ and $320^{\circ} \mathrm{C}$; it was noticed that thermocouples positioned on the left side recorded lower temperatures than thermocouples positioned on the right side (Figure 18). The thermocouples placed in the mortar recorded temperatures 


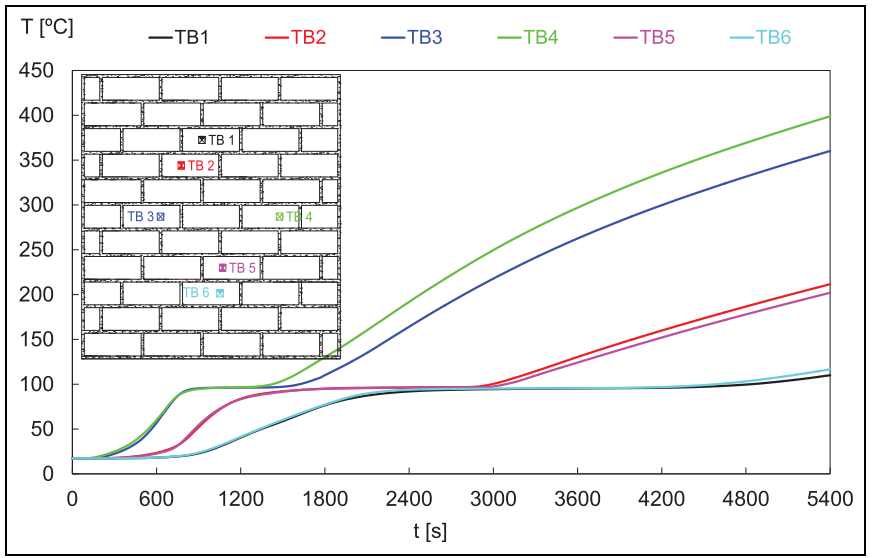

Figure 17. Time-temperature evolution inside the blocks (TB).

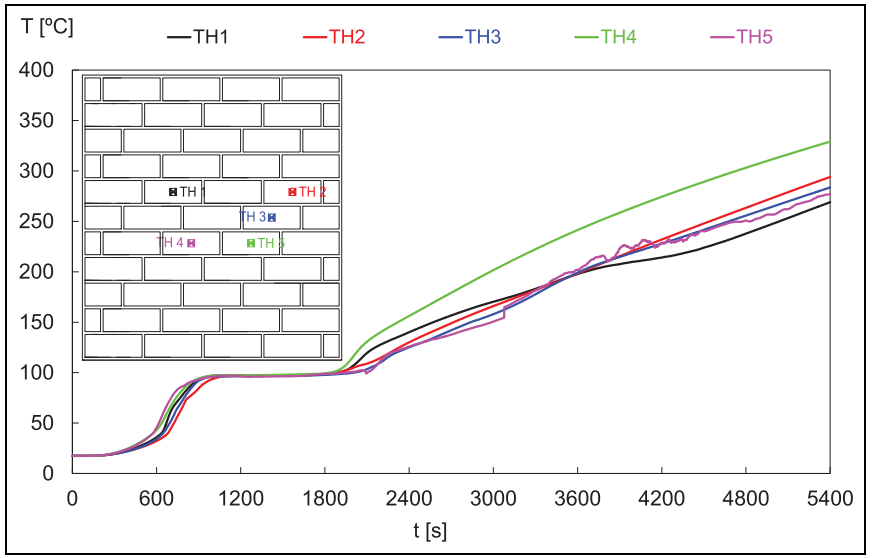

Figure 18. Time-temperature evolution inside the block holes (TH).

between $225^{\circ} \mathrm{C}$ and $325^{\circ} \mathrm{C}$; the thermocouples positioned in the centre of the panel recorded the higher values (see Figure 19).

From the analysis in Figure 20, one can see that the temperatures of the unexposed surface reached $90^{\circ} \mathrm{C}$ in all the thermocouples. According to EN $1363-1,{ }^{26}$ the insulation criterion was therefore verified. The addition of organic wastes does not seem to affect the capability of CEB walls to achieve fire safety criteria. Similar results were obtained from the work of Buson et al. ${ }^{7}$

Comparing Figures 17 to 19 , it is noticed that there is a plateau around the temperature of $100^{\circ} \mathrm{C}$. This is due to the moisture content in the panel. Later, the temperatures on the thermocouples begin to increase. In this process, the materials accumulate energy in an endothermic process. When the water evaporation ends, the measured temperatures increase again, following the same evolution slope as the initial behaviour.

Table 4 shows the obtained results of the compression tests on the CEB blocks after fire exposure. The obtained results are compared with the blocks tested without being exposed 


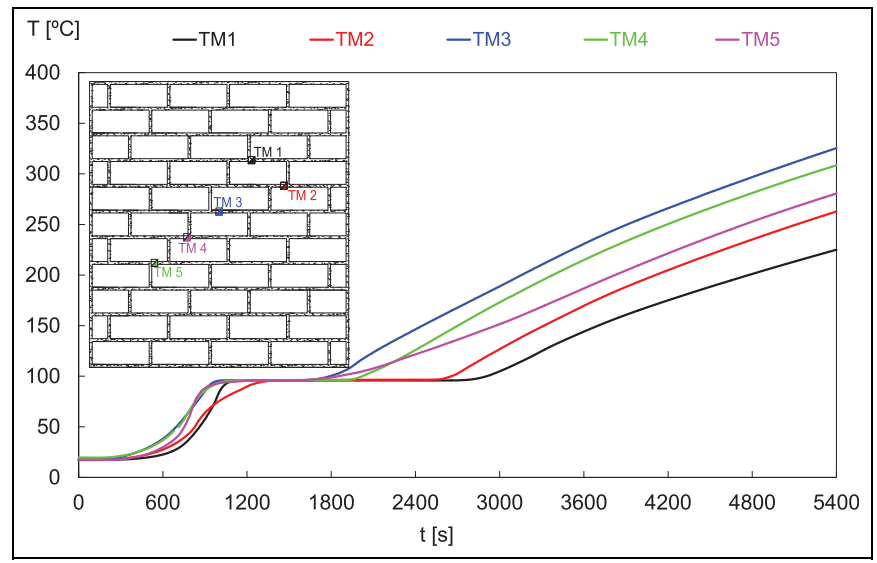

Figure 19. Time-temperature evolution in the mortar (TM).

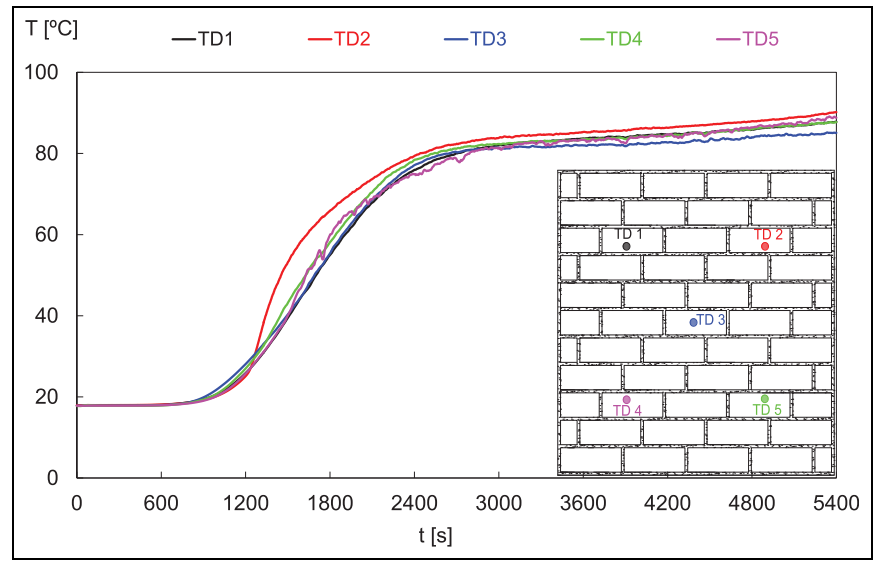

Figure 20. Time-temperature evolution in the unexposed surface (TD).

Table 4. Compression tests results in CEB blocks.

\begin{tabular}{|c|c|c|c|}
\hline & \multirow{2}{*}{$\frac{\text { Blocks without waste }}{\text { Blocks without fire exposure }}$} & \multicolumn{2}{|l|}{ Blocks with waste } \\
\hline & & Blocks without fire exposure & Blocks exposed to fire \\
\hline $\begin{array}{l}\text { Average results }(\mathrm{MPa}) \\
\text { Coefficient of variation }\end{array}$ & $\begin{array}{l}7.89 \\
0.02\end{array}$ & $\begin{array}{l}4.67 \\
0.11\end{array}$ & $\begin{array}{l}11.49 \\
0.12\end{array}$ \\
\hline
\end{tabular}

CEB: compressed earth block.

to fire. The results presented are the average of maximum stress obtained in 10 blocks tested in compression. 


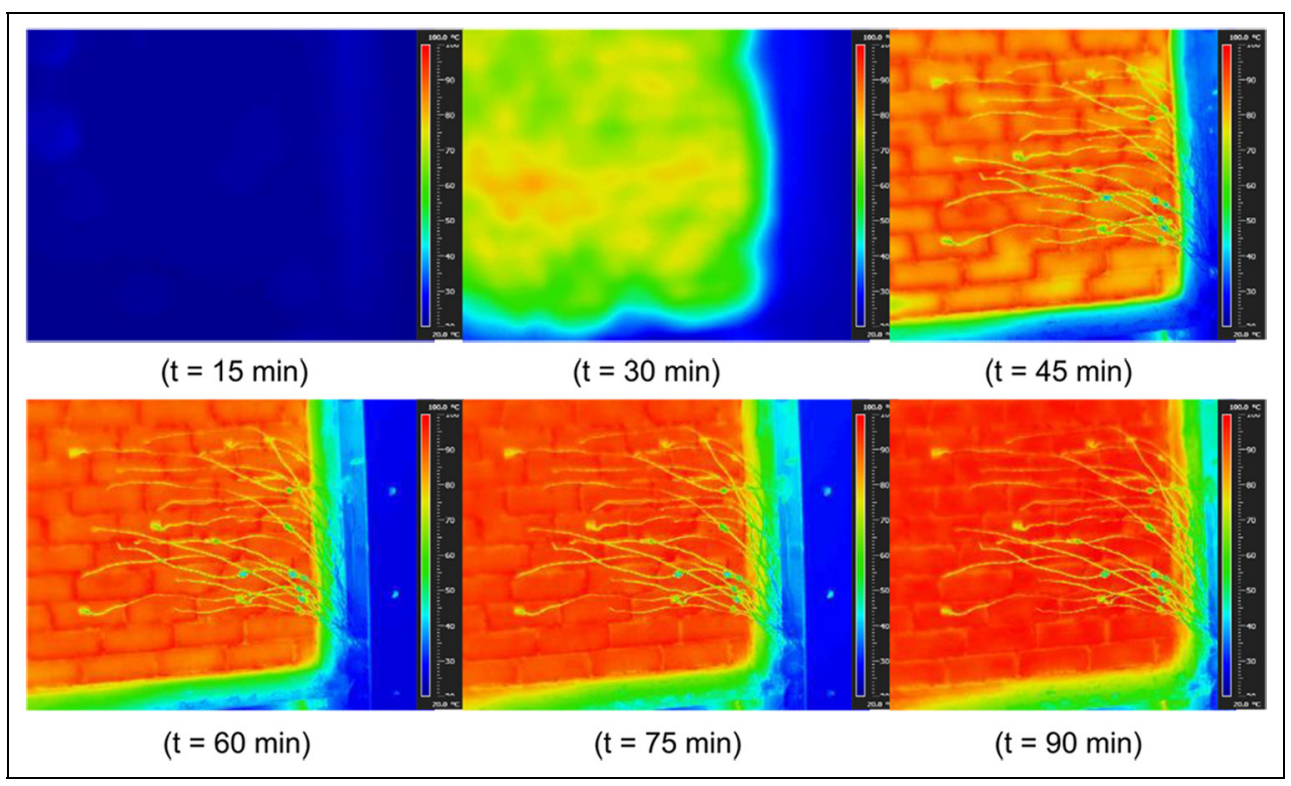

Figure 2I. Infrared thermograph diagrams of CEB wall panel.

One can observe that the results obtained in the blocks subjected to fire were higher than the results for the blocks without fire exposure, which is due to the cooking effect of the blocks. It is also observed that the non-waste blocks have a higher resistant capacity than the blocks with waste incorporation, in accordance with the previous results obtained in the mechanical characterization tests of the soil-cement samples. ${ }^{9}$

In Figure 21, one can see the infrared (IR) thermography diagrams at different testing stages. The results of the IR thermography complement the above ones since the surface temperatures of the entire unexposed surface of the panel can be assessed. In contrast, thermocouples measured the temperatures locally. This field measurement is of great importance to define the position of thermocouples used to find the maximum temperature events in future tests. Figure 21 shows the evolution of temperatures on the outer face of the CEB wall panel. According to the IR thermography, increase in temperature was noticed after $30 \mathrm{~min}$ and ranged to a maximum of $90^{\circ} \mathrm{C}$. Comparing the respective time-temperature evolution obtained by the thermocouples placed unexposed surface and using IR thermography, comparing these two data acquisition procedures, it is possible to figure out that there is adequate accordance.

\section{Numerical results of CEB wall panel}

The 3D wall model exposed to the ISO 834 standard fire curve is shown in Figure 22. All images are shown with the exposed face. The temperature gradient across the wall is similar for the CEBs and for the mortar elements. This is mainly due to the assumed perfect thermal contact between both the materials, neglecting any thermal conductance between the surfaces. In addition, CEB holes were modelled as cavities, leaving radiation between the 


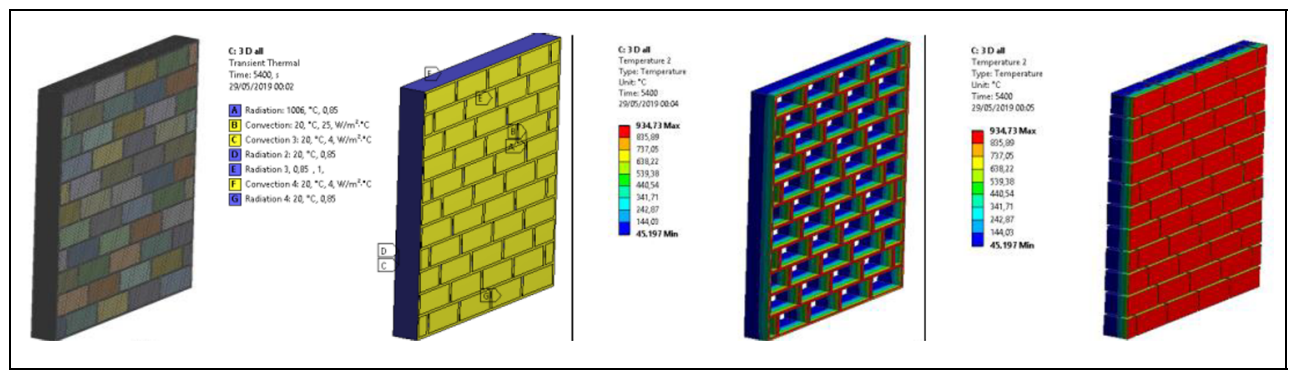

Figure 22. Finite element wall model with CEBs and mortar temperature fields.

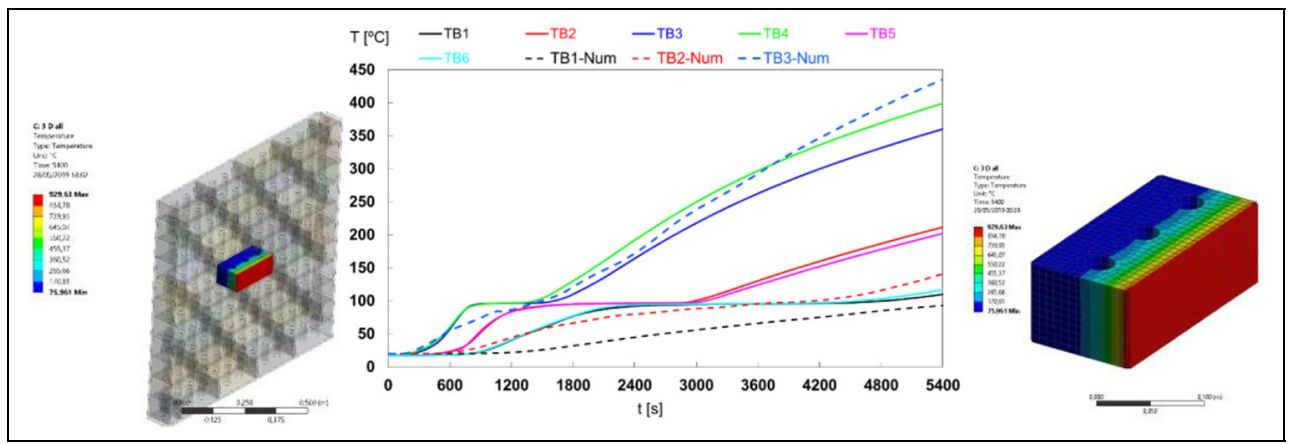

Figure 23. CEB temperature distribution and comparison between the experimental and numerical results.

surfaces possible. However, due to the temperature levels, no temperature gradient around the holes was found in comparison to the solid CEBs section.

Although convection and radiation heat losses were modelled in the contour wall faces, the major heat flux is through the wall thickness. This is evident in Figure 23, in which the experimental and numerical results are compared. This figure shows the temperature variation at three different points, corresponding to the depths of TB1, TB2 and TB3, defined in Figure 11.

The difference between the numerical and experimental temperatures increases from the exposed to the unexposed wall face. A higher difference is noticed for the TB1 position, which numerically stays below $100^{\circ} \mathrm{C}$. Even the dehydration experimental plateau is remarkably higher than the numerical, giving some evidence for a better definition of the thermal conductivity and specific heat in functions of temperature and water content.

\section{Conclusion}

The incorporation of waste into the soil-cement mixture allows another use for the compound, while saving the amount of soil and cement to be used. This article presents an experimental programme related to the fire behaviour of CEB walls, concerning its fire resistance.

The residual compression strength is also analysed. Testing samples were exposed to high temperatures and subjected to compression tests $24 \mathrm{~h}$ later. The samples show a significant 
loss of strength at $400^{\circ} \mathrm{C}$ demonstrating that, in the event of fire or exposure to high temperatures, negative modifications of materials after returning to room temperature cause a loss of resistance in the CEB. Therefore, caution is advised and a masonry strengthening strategy is recommended.

The CEBs panel, with the incorporation of wastes, was manufactured in the laboratory. The CEBs panel represents a portion of a real-scale wall, and all the dimensions are real ones, as can be seen in real buildings. The experimental results allowed to verify both the criteria (insulation and integrity) defined in the European standard for fire resistance tests.

The insulation criterion verification was conducted according to the relation between the average temperature increase and the average initial temperature, which was not higher than $140^{\circ} \mathrm{C}$. Moreover, the maximum temperature at any point of the unexposed surface of the CEBs panel did not exceed the final temperature of $180^{\circ} \mathrm{C}$. The integrity criterion was observed throughout the experiments, and no flame was identified. However, smoke released from burning CEBs was noticed from the middle of the test.

The temperature evolutions were linear up to $100^{\circ} \mathrm{C}$, and then a plateau corresponding to evaporation of the humidity of the blocks was noticed. After the moisture content in the panel had evaporated, the temperatures increase again with a similar slope as in the beginning.

The comparison between the numerical and experimental temperature results gives a higher difference on the unexposed wall side. It is evident the need to define clearly the CEBs' thermal property temperature variation.

The main concern with the occurrence of fire is not linked to the interest of preserving the heritage, but to ensure that the structure remains with its load-bearing capacity preserved for a period of time considered adequate to ensure fire-fighting and total evacuation of the people. In short, it can be said that earth constructions behave correctly when subjected to high temperatures, giving the necessary safety in the case of fire.

The incorporation of organic waste does not seem to affect the capability of CEB walls to accomplish the fire safety criteria.

\section{Acknowledgements}

The VALORCOMP project, supported by the FEDER through the INTERREG Program V-A SpainPortugal (POCTEP) 2014-2020, is acknowledged.

\section{Declaration of conflicting interests}

The author(s) declared no potential conflicts of interest with respect to the research, authorship and/or publication of this article.

\section{Funding}

The author(s) received no financial support for the research, authorship and/or publication of this article.

\section{ORCID iD}

Débora Macanjo Ferreira (iD https://orcid.org/0000-0002-5195-8265 


\section{References}

1. Barbosa $\mathrm{N}$ and Mattone R. Building with raw earth: I Seminário Ibero-Americano de Construção com terra. Brasil: Salvador, 2002, pp. 41-50.

2. Bati SB and Cinquina E. Earth material and buildings: sustainable constructions techniques. In: Proceedings of the international conference sustainability of constructions towards a better built environment, Innsbruck, 3-5 February 2011, pp. 103-110. Msida: University of Malta

3. Silva R, Soares E, Oliveira D, et al. CEBs stabilised with geopolymeric binders: mechanical performance of drystack masonry. In: Proceedings of the international conference on the environmental and technical implications of construction with alternative materials (WASCON), Santander, 10-12 June 2015.

4. Gomes MIS. Earthquake-resistant construction with raw earth. Master's Thesis, Instituto Superior Técnico, Lisboa, 2008.

5. Silva R, Soares E, Oliveira D, et al. Mechanical characterisation of dry-stack masonry made of CEBs stabilised with alkaline activation. Constr Build Mater 2015; 75: 349-358.

6. Nagaraj HB, Sravan MV, Arun TG, et al. Role of lime with cement in long-term strength of compressed stabilized earth blocks. Int J Sust Built Environ 2014; 3: 54-61.

7. Buson M, Lopes N, Varum H, et al. Fire resistance of walls made of soil-cement and Kraftterra compressed earth blocks. Fire Mater 2013; 37: 547-562.

8. Ferreira D, Luso E and Cruz L. Blocos ecológicos de solocimento comincorporação de resíduos. In: Proceedings of the 7th Euro-American congress construction pathology, rehabilitation technology and heritage management REHABEND 2018, Cáceres, 15-18 May 2018, pp. 1368 1376, https://bibliotecadigital.ipb.pt/bitstream/10198/ 18061/1/REHABEND_2018_BTC_res\%c3\%adduos.pdf

9. Nepomuceno EC.Use of municipal waste to build ecological blocks. Master's Thesis, School of Technology and Management, Polytechnic Institute of Bragança, Bragança, 2018.

10. Lima D, Soares E, Ferreira D, et al. Resistência termomecânica em regime estacionário de provetes de terra comprimida. In: Rodrigues JPC, Correia AM and dos Santos (eds) 6as Jornadas de Segurança aos Incêndios Urbanos - las Jornadas de Proteção Civil. ACIV Associação para o Desenvolvimento da Engenharia Civil ed. Coimbra: Universidade de Coimbra, 2018, pp. 59-71.

11. Ferreira D, Luso E, Cruz L, et al. Comportamento ao fogo de blocos ecológicos de solo-cimento com incorporação de resíduos orgânicos. In: Rodrigues JPC, Correia AM and dos Santos (eds) 6as Jornadas de Segurança aos Incêndios Urbanos-las Jornadas de Proteção Civil. Coimbra: Universidade de Coimbra, 2018, pp. 65-74.

12. ASTM D 2487-09:2000. Standard practice for classification of soils for engineering purposes (Unified Soil Classification System).
13. En 933-1:2012. Tests for geometrical properties of aggregates part 1: determination of particle size distribution.

14. EN 1097-6:2013. Tests for mechanical and physical properties of aggregates - part 6: determination of particle density and water absorption.

15. ASTM D 1817:1996. Standard test method for rubber chemicals: density.

16. ASTM D 281:1995. Standard test method for oil absorption of pigments by spatula rub-out.

17. ASTM D 4315:2017. Standard test methods for rubber compounding material: zinc oxide.

18. ASTM D 4318:2005. Standard test methods for liquid limit, plastic limit, and plasticity index of soils.

19. BS EN 197-1:2011. Cement part 1: composition, specifications and conformity criteria for common cements.

20. Portuguese republic diary. 1st series - No. 114. June 15, 2015. Decree-Law No. 103/2015, Ministry of Economy, Portuguese Republic, 2015 (Portuguese Legislation).

21. ASTM D 558:2011. Standard test method for moisturedensity relations of soil-cement mixtures.

22. ASTM D 1632:2017. Standard practice for making and curing soil-cement compression and flexure test specimens in laboratory.

23. Mansour MB, Ogam E, Jelidi A, et al. Influence of compaction pressure on the mechanical and acoustic properties of compacted earth blocks: an inverse multiparameter acoustic problem. Appl Acoust 2017; 125: 128-135.

24. CEN EN 1364-1:2015. Fire resistance tests for nonloadbearing elements - part 1: walls.

25. ISO 834-1:1999. Fire-resistance tests: elements of building construction.

26. CEN EN 1363-1:1999. Fire resistance tests - part 1: general requirements.

27. ANSYS. ANSYS theory manual. Canonsburg, PA: Technology Drive Canonsburg, 2013.

28. CEN EN 1992-1-2:2010. Eurocode 2: design of concrete structures - part 1.2: general rules, structural fire design.

29. Ferreira DM, Araújo A, Fonseca EMM, et al. Behaviour of non-loadbearing tabique wall subjected to fire: experimental and numerical analysis. J Build Eng 2017; 9: 164-176.

30. Mansour MB, Jelidi A, Cherif AS, et al. Optimizing thermal and mechanical performance of compressed earth blocks (CEB). Constr Build Mater 2016; 104: 44-51.

31. Zhang L, Gustavsen A, Jelle BP, et al. Thermal conductivity of cement stabilized earth blocks. Constr Build Mater 2017; 151: 504-511

32. Russell HW. Principles of heat flow in porous insulators. J Am Ceram Soc 1935; 18: 1-12.

33. Çengel YA. Introduction to thermodynamics and heat transfer. Boston, MA: McGraw-Hill, 1997.

34. Glicksman LR. Heat transfer in foams. In:Hilyard NC and Cunningham A (eds) Low density cellular plastics: physical basis of behaviour. Dordrecht: Springer, 1994, pp. 104-152.

\section{Author biographies}

Débora Macanjo Ferreira, $\mathrm{PhD}$ in Civil Engineering, is an adjunct professor at the Polytechnic Institute of Bragança and has research interests in sustainable building construction (earth, wood and stone), rehabilitation and bioclimatic construction, recycling and maximizing resources leading to the reduction of the environmental impact, and the behaviour of sustainable material under fire conditions. 
Eduarda Luso, PhD in Civil Engineering, is an adjunct professor at the Polytechnic Institute of Bragança and has research interests in the preservation of culture heritage, building materials, rehabilitation and bioclimatic construction, ecological soil-cement blocks, sustainable building construction, and reinforcement and consolidation of ancient masonry structures.

Maria Lurdes Cruz, Masters in Civil Engineering and a Fellow in VALORCOMP project, has research interests in soil-cement blocks, ecological material, sustainable building construction and recycling materials.

Luís MR Mesquita, $\mathrm{PhD}$ in Mechanical Engineering, is an adjunct professor at the Polytechnic Institute of Bragança, where he is a lecturer since 2001. His current research topics include experimental, numerical analysis and behavior of structures and materials in fire.

Guilherme Gontijo, technician in Edifications through the Federal Center of Technological Education of Minas Gerais, is currently a bachelor student in Civil Production Engineering at the Federal Center of Technological Education of Minas Gerais, attending a double degree program for Masters in Construction Engineering through the Instituto Polytechnic Institute of Bragança. 